\title{
A EXPANSÃO DA CAFEICULTURA E O DESENVOLVIMENTO DA AGROINDÚSTRIA AÇUCAREIRA DE SÃO PAULO ${ }^{1}$
}

Silvio Carlos Bray

Prof. Dr. do Dep. de Planejamento Regional, UNESP, Rio Claro

\begin{abstract}
RESUMO: Neste artigo, queremos discutir a respeito dos trabalhos que versam sobre a agroindústria açucareira em S. Paulo e que levantaram como paradigma as sucessivas crises do café na aplicação do desenvolvimento das Usinas Paulistas, entre o final do séc.XIX e primeiras décadas deste século.
\end{abstract}

Palavras Chaves: Agroindústria, Café, Açúcar.

SUMARY: In this article we can argue about sugar Agro-industry works in S. Paulo State (Brazil) and, that's been standed as paradigm, the successive coffee crises in explanation of "Paulistas"(from S.Paulo) manufactory development, in the last 1995 and the first decade in this Century.

Key Words: Agro-Industry, Coffee, Sugar.

O objetivo deste artigo é discutir os trabalhos que versam sobre a agroindústria açucareira, em São Paulo, e que levantaram como paradigma as sucessivas crises do café na explicação do desenvolvimento das usinas paulistas, entre o final do século $X I X$ e as primeiras décadas deste século. Nesse período, o estado de São Paulo passou a ter de 667 fazendas de cana, em 1852, para 2494 engenhocas e oito usinas, em 1900, justamente na fase de maior expansão da cafeicultura paulista.

Sendo as áreas cafeeiras onde as relações capitalistas mais se desenvolveram no país, aí também será encontrada a maior parte da nascente indústria nacional. Entretanto, a cultura cafeeira teve momentos de apogeus e crises e é justamente dentro deste contexto que se expandiu a indústria açucareira paulista.
CARLI (1943) caracterizou o avanço da lavoura canavieira em São Paulo da seguinte maneira:

\begin{abstract}
"Se bem não tivesse existido em São Paulo uma luta econômica das duas culturas - a do café e a da cana-de-açúcar - toda a vez que a lavoura cafeeira era atingida pela crise, e elas foram periódicas, melhorava a situação de progresso da lavoura canavieira. Havia uma maior atração para o produtor que tinha a garantia de um mercado interno, quando $o$ café, produto de mercado internacional, deixava de ser uma fonte de grande riqueza".
\end{abstract}

Esta tese de CARLI (1943) mostra que, graças às crises sucessivas do café, expandiase a lavoura canavieira e, consequentemente, a agroindústria açucareira em São Paulo. As raízes desta explicação resultam da afirmação de que a industrialização em São Paulo se faz no momento das crises do café, que foi

\footnotetext{
1 Este artigo é dedicado à memória do Prof.Dr.José Ribeiro de Araújo Filho.
} 
defendida por Roberto Simonsen e, posteriormente, Celso Furtado (Reis Garcia, 1985).

Esta perspectiva na explicação da formação e expansão da industrialização do açúcar, em São Paulo, através das crises sucessivas do café, foram exploradas e repetidas por todos os estudiosos da agroindústria açucareira paulista até os dias de hoje, via Gileno de Carli.

Encontramos esta visão de CARLI (1943) primeiramente em QUEDA (1972):

"As crises sucessivas do café acabaram, de certa forma, favorecendo o reaparecimento da cana-de-açúcar nas áreas de Campinas, Piracicaba e Porto Feliz, quando os ganhos com os negócios do café experimentaram fortes baixas".

As colocações de QUEDA (1972) envolvem duas interpretações. Uma coloca que a cultura da cana-de-açúcar reapareceu nas áreas tradicionais, como se ela tivesse um dia desaparecido. A outra aponta a crise do café como geradora de novos empreendimentos no setor açucareiro, o que estamos agora questionando.

Também em GNACCARINI (1972), encontramos esta via de explicação para a ascensão da agroindústria açucareira:

"Nas duas primeiras décadas deste século, a produção de açúcar paulista já se expandia grandemente, tanto em virtude da ampliação do mercado consumidor de açúcar no próprio Estado, como em consequência da inversão de capitais na indústria açucareira, os quais haviam sido liberados pela crise do café. Antigos fazendeiros-comerciantes de café como Nogueira, Alves, Dumont, Junqueira, Schmidt, Ferreira Ramos, Pimentel, Miranda, Pinto, tornaram-se grandes usineiros, e, em muitos casos, passaram a dedicar-se exclusivamente à produção açucareira. Nessa época, algumas dessas firmas entraram também no comércio atacadista de açúcar, e etc (...)".
Também BRAY (1980), citando Carli, reproduz: "Assim, em função das crises sucessivas do café em São Paulo, iam surgindo novos canaviais".

Esta mesma linha de explicação pode também ser encontrada em RAMOS (1983), que referenda e continua reproduzindo a interpretação: "a inversão de capitais na indústria açucareira, haviam sido liberados pela crise do café".

Carli mostrou que não só as crises do café levaram à expansão da produção açucareira, mas, em alguns momentos, também os lucros do café. Nestas colocações, podemos notar que, apesar do autor apoiar-se nas crises sucessivas do café para explicar o avanço da cultura canavieira em São Paulo, o referido autor não deixou de vislumbrar a possibilidade dos lucros auferidos pela cafeicultura terem sido deslocados no desenvolvimento da agroindústria açucareira paulista.

Por outro lado, GNACCARINI (1972) aponta o seguinte:

"Pode-se verificar que a expansão açucareira se fez precisamente nos anos que se seguem às crises do café, logo depois das grandes crises de 1913 e 1921. Muitos dos fazendeiros e sitiantes de café substituiramno, então pelo açúcar, fazendo dobrar a produção entre 1910 e 1921. Este crescimento está ligado, ainda, à ampliação do mercado interno que o crescimento da economia cafeeira, com a imigração, a urbanização e o esforço da industrialização, propiciou. Quase todos os grandes grupos usineiros desse período tiveram origem na produção do café. De um total de dezesseis usinas, arroladas em 1920, apenas cinco não se incluíam nessa categoria, sendo que quatro destas pertenciam a uma sociedade de capitais franceses. Em estatísticas de 1922 e 1923, aparecem arroladas mais quatro outras usinas, das quais é certo que, pelo menos três, tiveram origem nos negócios de produção de café". 
Não podemos concordar com as colocações de Gnaccarini, pois queremos salientar que ocorreram generalizações na análise do processo da formação das agroindústrias de São Paulo, no referido período.
Das 8 usinas fundadas, entre os anos de 1911 e 1922, 5 (cinco) delas foram instaladas na zona de Ribeirão Preto e Araraquara, na época as principais e mais ricas áreas cafeeiras do Estado, conforme Figuras 1 e 2, com cafezais novos e de alta produtividade, portanto bastante lucrativos nos anos dez e vinte.

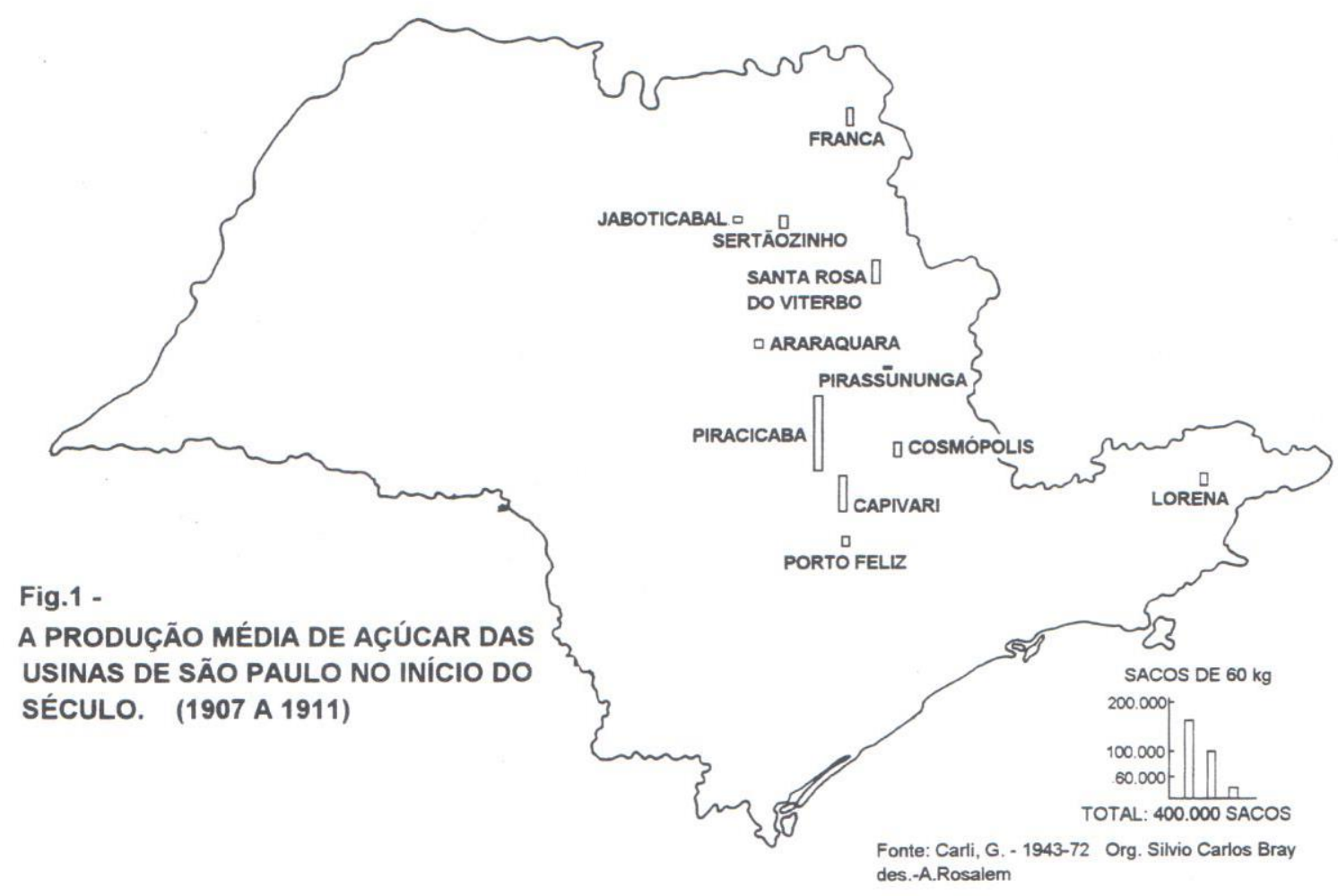




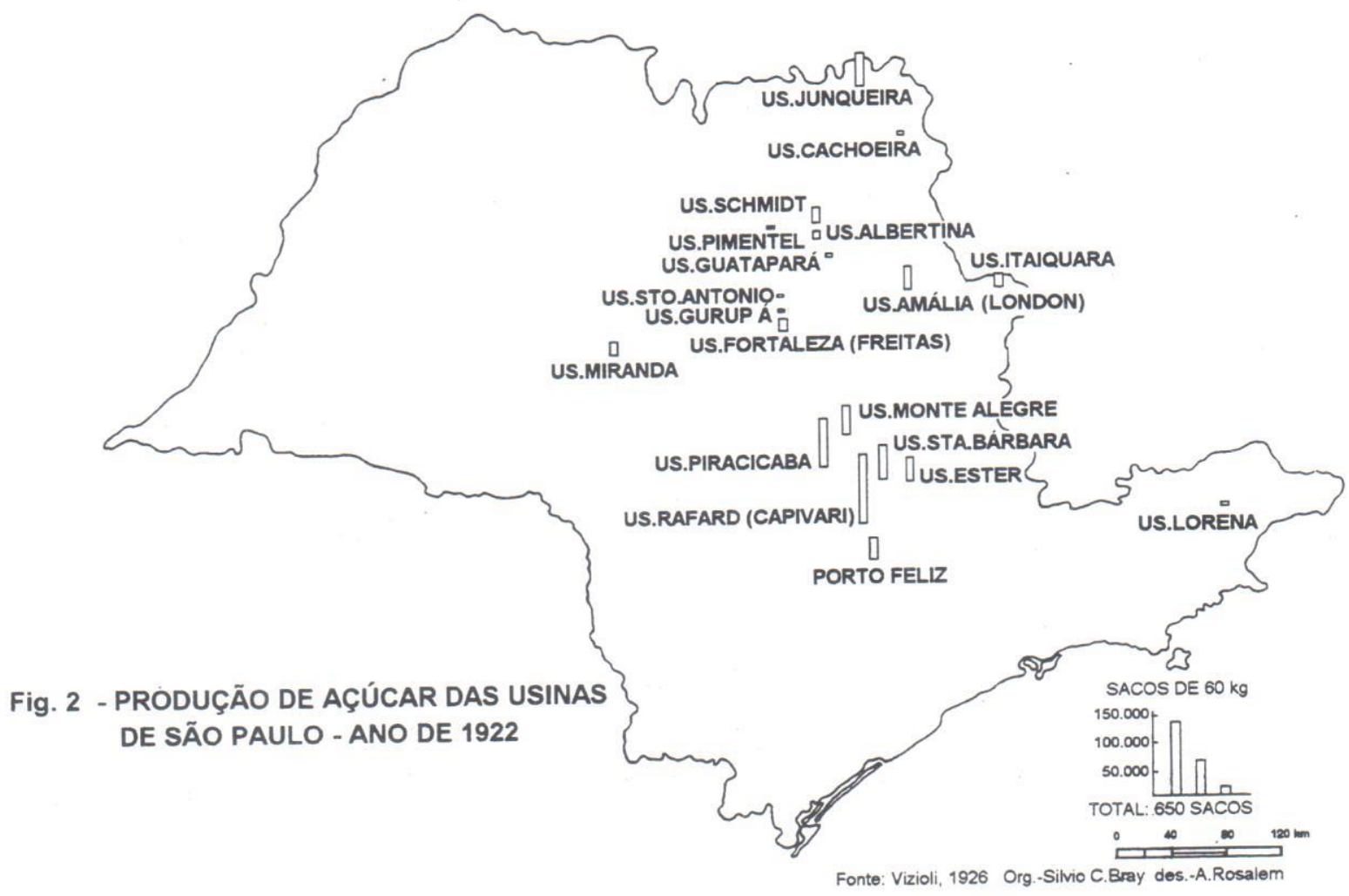

Pirajuí caracterizava-se como o pólo cafeeiro mais avançado (Figuras 2 e 3 ) e altamente produtivo do "Oeste Novíssimo", com cafezais recentes em pleno centro do Planalto Ocidental Paulista. Portanto, a Usina Miranda foi instalada em áreas de cafezais novos e não de cafezais decadentes, onde a cana os havia substituído, conforme as colocações de Gnacarrini.
Também, observando as figuras 2 e 3 , a Usina Itaiquara foi instalada em Caconde (hoje as instalações fazem parte do município de Tapiratiba), em plena zona de cafezais novos e lucrativos dos contrafortes da Mantiqueira Paulista. Caso semelhante também ocorreu com a implantação da Usina Junqueira, em Igarapava. 


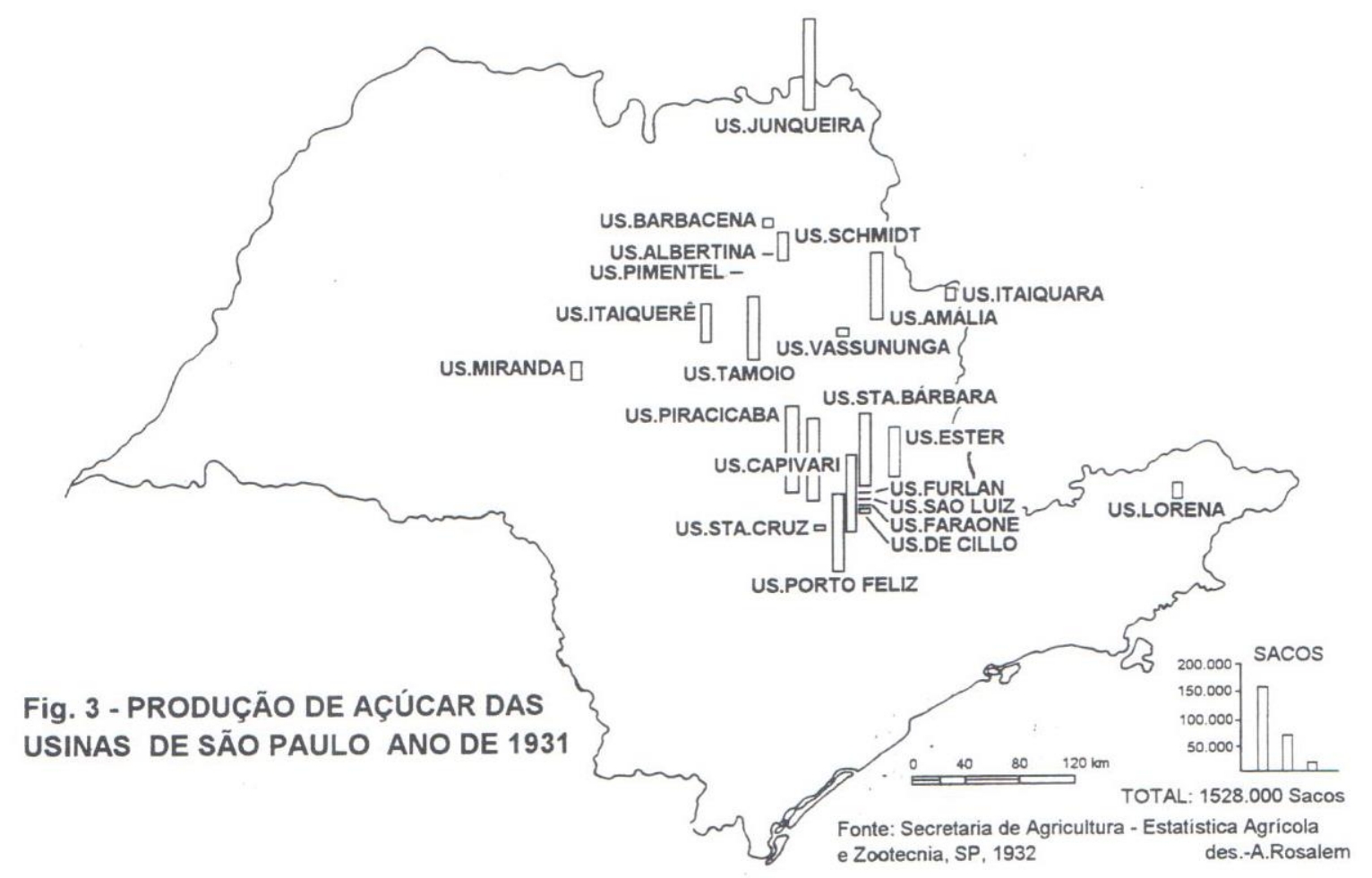

Através dessas considerações mais pormenorizadas da questão, não poderíamos concordar com as colocações de Gnaccarini, uma vez que as usinas implantadas, no período citado, localizavam-se nas áreas onde se concentravam os cafezais mais novos e produtivos do Estado. A nosso ver, estas usinas tiveram as suas origens ligadas, principalmente, aos lucros advindos dessas novas e ricas regiões cafeeiras de São Paulo dos anos dez e início dos anos 20, assunto que discutiremos melhor no próximo item.

Sobre o valor empresarial dos fazendeiros de café em São Paulo, DEAN (1971) diz:
“Entretanto, quando se propõem explicações para o valor empresarial dos fazendeiros, não se deve passar por alto o reverso do argumento: por que havia tão pouca competição de outros grupos econômicos, tanto internos quanto externos? Outra razão importante é que os fazendeiros controlavam a máquina do governo e usavam-na constante e eficazmente em favor de seus interesses (...) Quando da queda do Império em 1889, Ihes ensejou a oportunidade de melhorar sua posição, advogaram na Assembleia Constituinte a descentralização política, que proporcionou a São Paulo todos os elementos essenciais da soberania com pouquíssimos ônus: o controle das terras imperiais, o direito de tributar a exportação $e$ de agenciar empréstimos no exterior (...) os 
fazendeiros se limitavam, quase sempre, a empreendimentos que o governo estadual podia conseguir a guisa de monopólio (...). As estradas de ferro receberam "zonas privilegiadas" e garantias de lucro, que, por volta de 1904, haviam custado ao governo de São Paulo o equivalente a quarenta milhões de dólares. Garantias semelhantes se concederam às usinas de açúcar".

É dentro desse enfoque, ou seja, do papel empresarial do fazendeiro de café no desenvolvimento da agroindústria açucareira, através do complexo-cafeeiro capitalista paulista, que destacaremos, no item a seguir, os cafeicultores Dr. Dumont e Cel. Francisco Schmidt.

Retomando a historiografia mais recente, DEAN (1971) critica esta idéia clássica de Roberto Simonsen, retomada por Furtado, mostrando que, na realidade, existiu uma relação positiva entre café e indústria, pois, quando o café vai bem, a indústria também atinge sua prosperidade (Reis Garcia, 1985).

Esta tese de Dean, também é endossada por CANO (1977) que coloca o seguinte:

"se visto o conjunto da atividade cafeeira, o mecanismo do ciclo encobre 0 funcionamento e a ação das partes constitutivas do todo cafeeiro, ou seja, quando se dá uma grande onda de expansão do plantio, por exemplo, a de 1886/97, as plantações feitas no início dessa onda - 1886 - enquanto ainda segue a onda expansionista para as demais frações do todo cafeeiro. Assim, parte desses novos lucros podem perfeitamente se transferir direta ou indiretamente da atividade nuclear para a indústria, mesmo que a expansão do plantio siga por mais tempo".

"Creio, (...) que a expansão diversificada da agricultura paulista não ocorria, apenas, em função das crises cafeeiras. Como se viu, ela ocorre tanto nas crises como nas fases de expansão do café e isso se deve, a meu juízo, pela crescente independência que a agricultura praticada fora da propriedade cafeeira vai adquirindo, à medida que o mercado urbano se expandiu".

Sobre o assunto, DEAN (1971) aponta que:

"O desejo de tornar mais lucrativas as propriedades agrícolas foi, igualmente, uma das molas dos primeiros empreendimentos manufatureiros. Na década de 1880 , construíram-se várias refinarias de açúcar na área de Piracicaba, também como sociedade anônima. Quatro delas caíram nas mãos de uma companhia francesa, que já possuía fábricas na província do Rio de Janeiro, mas outras ainda foram construídas por fazendeiros na área de Ribeirão Preto, mais para o norte, provavelmente com os lucros do café. Estas acabaram suprindo a maior parte do mercado interno".

É dentro dessa abordagem "caféagroindústria açucareira" que estamos retomando as colocações citadas acima e procurando romper com CARLI (1943) e as demais interpretações que se sucederam na explicação do avanço da cana-de-açúcar, apoiadas no referido autor.

Neste sentido, procuramos demonstrar que o avanço da cultura canavieira paulista não dependeu apenas das crises sucessivas do café, mas sim do deslocamento contínuo dos lucros da cafeicultura para os negócios da industrialização do açúcar.

Para rompermos com esse paradigma que orientou os trabalhos sobre a agroindústria açucareira de São Paulo até os dias de hoje, nos baseamos em dois estudos de casos de dois grandes cafeicultores de São Paulo, da região de Ribeirão Preto, nos finais do século XIX e primeiras décadas deste século: os senhores Dr. Henrique Santos Dumont e o Cel. Francisco Schmidt, fazendeiros estes que deslocaram capitais, nos períodos de apogeus e crises do café, para os negócios da industrialização e comercialização do açúcar. 


\section{O caso Dr. Henrique Santos Dumont}

Procuramos abordar o caso do Dr. Henrique Santos Dumont em duas fases. A primeira abrangendo o período em que foi fundador e proprietário da Companhia Agrícola Fazenda Dumont, no município de Ribeirão Preto, quando se caracterizou como o maior comprador de terras, por volta da penúltima década do século XIX, e tornou-se o primeiro rei do café da região. A segunda, analisada por Bray (1989), quando vende a Companhia Dumont e compra a fazenda Amália, montando a usina London, na última década do século passado, no município de São Simão.

\section{A Companhia Agrícola Fazenda Dumont}

O Dr. Dumont (que era irmão de Santos Dumont) foi um engenheiro francês que se tornou um coronel do café brasileiro. Após ter exercido a sua profissão no Brasil, durante alguns anos, passou a trabalhar para o sogro como administrador de uma fazenda de café, no município de Valença, no Estado do Rio de Janeiro.

Após 1879, separou-se do sogro, que faleceu dois anos mais tarde, conseguindo acumular bens próprios e de herança o suficiente para se tornar um grande cafeicultor.

A divulgação da venda de terras de boa qualidade em Ribeirão Preto levou Henrique Dumont para a região, adquirindo a primeira propriedade em 1879.

Sobre as compras de terras de Dumont na zona de Ribeirão Preto, Zamboni (1979) coloca o seguinte:

"Henrique Dumont foi o maior comprador de terras por volta da penúltima década do século passado, sendo que o grande comprador da última década foi o coronel Francisco Schmidt (...).
Houve uma forte concentração da propriedade agrária da região. Os grandes produtores de café aumentaram suas áreas para estender seus cafezais, e não só Henrique Dumont se utilizou desse processo, como também o coronel Francisco Schmidt comprou muitas propriedades (...)".

Em 1890, o Dr. Dumont constituiu a Companhia Agrícola Fazenda Dumont (C.A.F.D.), mas já na década de 1880 , aproveitando a penetração da Mogiana em Ribeirão Preto, em 1883, construiu um ramal ferroviário até as suas terras.

\section{E ZAMBONI (1979) aponta:}

"Enfim, Henrique Dumont se torna o primeiro rei do café da região, possuindo aproximadamente 6.000 alqueires localizados parte em Sertãozinho e parte em Ribeirão Preto, com 5 milhões de cafeeiros em plena produção".

Com a ampliação das fazendas cafeicultoras, no início da década de 1880 ,a imigração se iniciou na região de Ribeirão Preto e na Fazenda Dumont, mesmo antes da abolição da escravatura.

Em 1891, Dumont vende quase a maioria das ações da Companhia Agrícola Fazenda Dumont à Companhia Melhoramentos do Brasil. Sobre esta venda, ZAMBONI (1979) diz:

"Segundo o Diário Oficial do Estado de São Paulo (7/4/1892) das 42.000 ações da Companhia Agrícola Fazenda Dumont, 41.375 pertenciam à Empresa Industrial Melhoramentos do Brasil, e as restantes 1.125 ações estavam distribuídas entre os vários Dumont, Villares e Paulo de Frontim".

\section{A Fazenda Amália e a Usina London}

O Dr. Dumont, após ter sido o maior fazendeiro do café de Ribeirão Preto e após ter vendido a Companhia Agrícola Dumont, no início 
da década de 1890, comprou a fazenda Amália, idealizou e fundou a agroindústria açucareira London, nos últimos anos do século XIX, no município de São Simão (hoje essas terras pertencem ao município de Santa Rosa do Viterbo).

A Fazenda Amália foi adquirida da Empresa Industrial Melhoramentos do Brasil (a mesma a quem foram vendidas as ações da Cia. Dumont), da gleba denominada "Fazenda Constança", e custou ao Dr. Dumont e sua esposa, Dona Amália Ferreira Dumont, 146 contos de reis, em 18 de janeiro de 1894.

A partir de então o Dr. Dumont passa a adquirir mais terras em torno desta primeira fazenda. No mesmo ano adquire mais três fazendas vizinhas. Em 1895, compra mais uma propriedade e, em 1897, mais três, todas unidas às anteriormente adquiridas. No ano seguinte compra mais duas fazendas.

Em 1898, o Dr. Dumont inicia a derrubada das matas, planta café e introduz o plantio da cana-de-açúcar nas propriedades Constança, Peroba e Coqueiros, através de um contrato com três empreiteiros.

Em 1898, começa a construção de um ramal ferroviário, desde a Estação Glória (na Estrada de Ferro Mogiana) até as barrancas do Rio Pardo (conhecido como Corredeira Velha), cortando as terras de sua propriedade. A Estação Santos Dumont, antiga Estação Glória, localiza-se entre São Simão e Tambaú. O ramal, construído pelo Dr. Dumont, passa por Santa Rosa do Viterbo e pela sede da Usina London (hoje Amália), e foi inaugurado como ramal ferroviário, em 1899.

Nesse período, 1894 a 1899, o Dr. Dumont ainda comprou os equipamentos $e$ montou a fábrica. Segundo SAWYER (1905):
"O proprietário, depois de ter estudado a fundo todos os sistemas de fabricação conhecidos, acabou por adquirir os aparelhos do antigo Engenho "Rio Bonito", Barra do Piraí, Estado do Rio de Janeiro, construído pelos antigos estabelecimentos CAIL em 1886 e montou-os em London".

Após alguns anos, o Dr. Dumont vendeu os maquinários ao Cel. Francisco Schmidt, adquirindo uma fábrica maior em Cachoeiro do Itapemirim, no Estado do Espírito Santo. ${ }^{2}$

Sobre o canavial da London, no início do século, SAWYER (1905) diz:

"O Engenho pertence ao Dr. Henrique Santos Dumont; nós o visitamos e também as plantações no mês de maio de 1904. Do lado do Rio Pardo vimos bem boas plantações de cana rosada, em covas bem distanciadas em terrenos recentemente arroteados. Em certos lugares baixos e férteis estas canas tinham até 3 metros de comprimento. (...) Segundo as estimativas do Dr. Dumont ele tinha 1200 hectares de canaviais dos quais 720 para cortar em 1904, sendo uma metade canas novas e a outra sequeiras".

Em 15 de dezembro de 1909, o Dr. Dumont vendeu para a Companhia Mogiana de Estradas de Ferro o ramal que construiu até o Rio Pardo. A Cia. Mogiana construiu a ponte sobre o Rio Pardo e estendeu o ramal até a cidade de Cajuru, inaugurando esse prolongamento em 1912.

De 1907 a 1919, o Dr. Dumont adquiriu, para a sua agroindústria, mais 11 propriedades rurais, abrangendo parte das terras de fazendas que já havia adquirido e novas glebas.

No ano de 1915, conforme Tabela n 01 , o Dr. Dumont apresentava-se como o maior produtor de café do município de Santa Rosa do Viterbo, com 750.000 pés plantados, num

\footnotetext{
2 ODr.Schmidt deve ter utilizado os equipamentos comprados nos dois engenhos simples em Ribeirão Preto, ou na Usina Cachoeira de Franca, ou ainda, na Usina Schmidt, que fundou em Sertãozinho.
}

Sociedade \& Natureza, Uberlândia, 10 (19): 45-56, janeiro/junho 1998 
total municipal de 2.286 .000 cafeeiros produzindo.

Em 25 de maio de 1920, com o falecimento do Dr. Henrique Santos Dumont, a Usina London e suas terras foram vendidas ao
Conde Francisco Matarazzo, à Cia Mecânica e Imp. de São Paulo e ao Cel. Francisco Schmidt e passou então a denominar-se Sociedade Agrícola Fazenda Amália, em homenagem a D. Amália, esposa do Dr. Henrique Dumont.

\section{TABELA NO 1}

Principais Produtores de Café do Município de Santa Rosa do Viterbo, no ano de 1915.

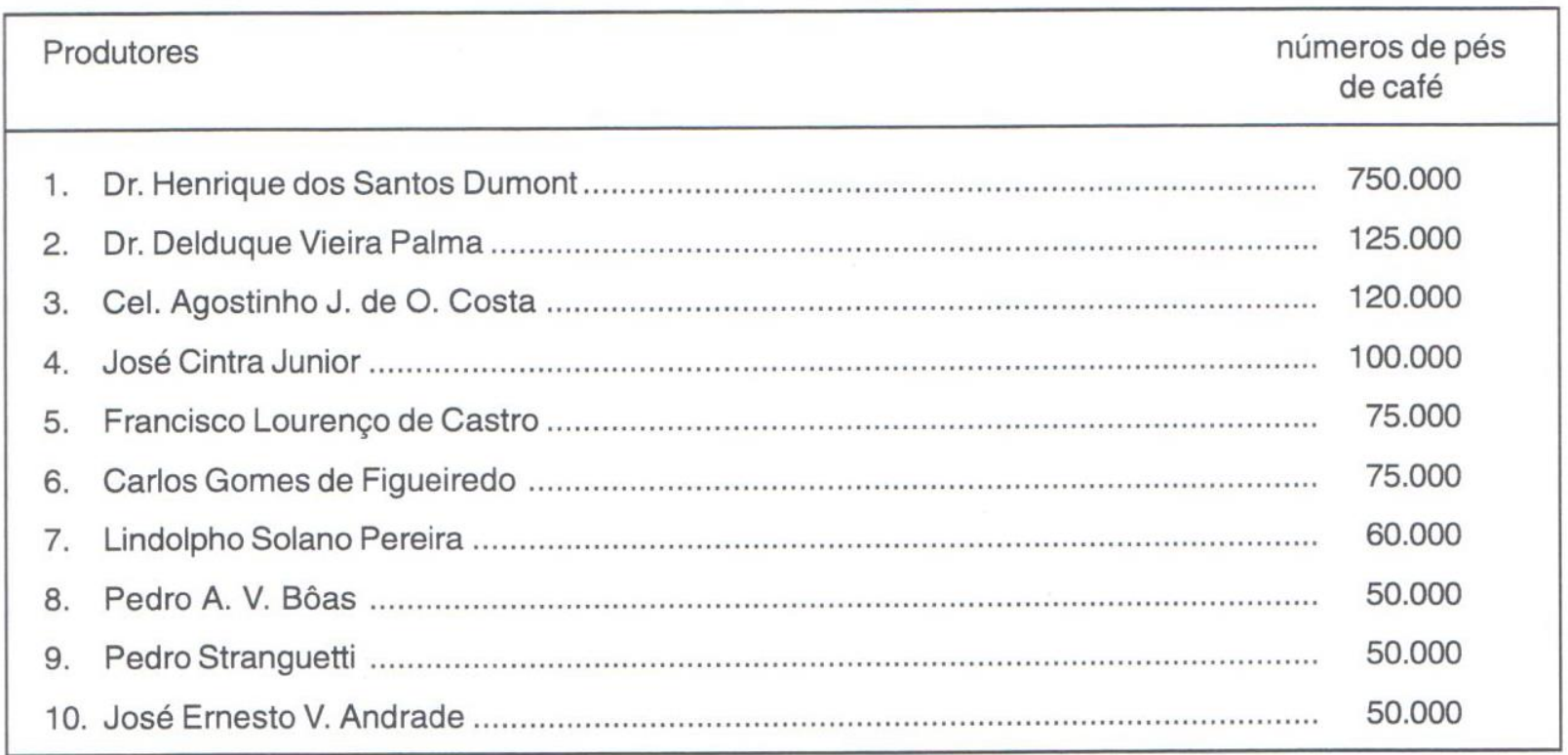

Fonte: O Café, Estatísticas de Produção e Comércio da Secretaria da Agricultura Indústria e Comércio e Obras Públicas do Estado de São Paulo, 1915, p. 145

\section{O caso Cel. Francisco Schmidt}

Sobre a formação e a expansão do patrimônio econômico de Francisco Schmidt dentro da economia cafeeira paulista, temos um interessante trabalho de MELLO MORAES (1982), produto de sua Dissertação de Mestrado.

Francisco Schmidt tinha oito anos de idade quando veio da Alemanha para o Brasil, juntamente com a família, para trabalhar numa fazenda de café no município de São Carlos.

Durante vinte anos, trabalhou como colono, até comprar um armazém de secos e molhados na cidade de Descalvado, em 1878. Tornando-se um próspero comerciante e tendo grande visão comercial, via no mercado cafeeiro da região grandes possibilidades de acumulação. E, em 1889, voltou-se para a cafeicultura, conforme as colocações de MELLO MORAES (1982):

"Vendeu seu estabelecimento em Descalvado e aplicou o capital na compra de sua primeira fazenda, denominada Bela Paisagem, no município de Santa Rita do Passa Quatro. Entretanto, durante pouco tempo ficou com esta fazenda, vendendo-a logo depois". 
No ano seguinte (1890), Schmidt tornouse sócio de Arthur Aguiar Diederichsen, também de origem alemã, adquirindo a Fazenda "Monte Alegre", em Ribeirão Preto. No mesmo ano, Schmidt comprou a parte de Diederichsen, e MELLO MORAES (1982) mostra a expansão desse cafeicultor:

\begin{abstract}
"A partir da compra da fazenda Monte Alegre, Francisco Schmidt foi adquirindo outras propriedades agrícolas, não só em Ribeirão Preto, mas também em outros municípios do Estado. Todas as transações comerciais de Francisco Schmidt a partir dessa época, 1890, até o início da Primeira Guerra Mundial, 1914 , foram efetuadas com financiamento da firma Theodor Wille \& Co., a quem fora apresentado pelo seu ex-sócio e particular amigo Arthur Aguiar Diederichsen. No período de guerra, 1914-1918, a Theodor Wille suspendeu as operações financeiras com Francisco Schmidt'3
\end{abstract}

De 1890 a 1899, Francisco Schmidt adquiriu 12 (doze) fazendas no município de Ribeirão Preto, que totalizavam 2.935 alqueires de terras, com 2.413.910 pés de café. A respeito da aplicação de seus lucros em novos empreendimentos MELLO MORAES (1982) diz:

"Conhecendo as condições do mercado cafeeiro, Francisco Schmidt soube aproveitar as oportunidades empregando os seus lucros na compra de novas fazendas e especulando no mercado de terras (...). A própria lavoura de café se autofinanciava, permitindo a acumulação de capitais, que eram empregados em novas lavouras e em outros setores econômicos, como ferrovias, indústrias, serviços urbanos, etc. (...)".

Em virtude de MELLO MORAES (1982), ao tratar da expansão das propriedades do Cel. Francisco Schmidt, ter-se utilizado principalmente da história oral - através de entrevistas realizadas com o Sr. Jacob Schmidt - notamos a falta de algumas informações que se encontram esparsas em vários estudos sobre a agroindústria açucareira paulista. Após as aquisições de terras de Francisco SCHMIDT, em 1899, no município de Ribeirão Preto, MELLO MORAES (1982) só cita a compra, por volta de 1905 ou 1906, de um fazenda no atual município de Pontal, anteriormente pertencendo ao município de Sertãozinho, e coloca:

\begin{abstract}
"Posteriormente, Francisco Schmidt passou a comprar fazendas em outros municípios do Estado de São Paulo. Em Pontal, adquiriu uma fazenda que, segundo seu filho Jacob Schmidt, teve pouco sucesso, porque o terreno não era próprio para a plantação de café. Resolveu então instalar um engenho de açúcar nesta fazenda. Foi à cidade de Campos, no Estado do Rio de Janeiro, estudar o funcionamento de um engenho. Em 1906 instalou o primeiro engenho da região, - Engenho Central, que produzia cem sacos de açúcar por ano. Este fato evidencia o desenvolvimento da empresa de Francisco Schmidt através de uma diversificação de atividades, investindo em outros setores da produção. Mais tarde montou outro engenho, o de São Miguel, no mesmo município. Também no setor pastoril Francisco Schmidt investiu grande capital: os seus rebanhos de raça caracu obtiveram por várias vezes os primeiros prêmios, atingindo os rebanhos mais de 14 mil cabeças".
\end{abstract}

Podemos observar que faltaram para Mello Moraes algumas informações, pois que o Engenho Central, conhecido como Usina Schmidt de Sertãozinho, não foi a primeira usina da região, uma vez que já existia a Usina INDAIÁ e CACHOEIRA (1898) e a Usina LONDON (1899). Além disso, antes da Usina Schmidt de Pontal, que foi fundada em 1906, o Cel. Schmidt adquiriu a Usina Cachoeira, no município de Franca, no ano de 1903. Concluímos ser no ano

\footnotetext{
3 A firma Theodoro Wille \& Co. era uma grande firma alemã, que até 1870 dedicava-se à exportação de cana-de-açúcar e algodão. Após essa data passou a dedicar-se aos negócios do café. A firma possuía várias fazendas de café na região da Araraquarense, controlava empresas de energia elétrica e uma indústria têxtil. Também possuía ligações financeiras com a Brasileanische Banck e o Deustche Uberseeische Banck. Após a $1^{\text {a }}$ Guerra, a firma Wille voltou a manter operações financeiras com Schmidt (Mello Moraes, 1982).
} 
de 1903 que tenha ocorrido a transação, pois entre 1901 e 1902 esta usina não constava na relação da Secretaria da Agricultura. Entretanto, em 1904 foi visitada por SAWYER (1905), que fez um relato sobre a referida fábrica: "Este engenho foi montado em $1898 \mathrm{com}$ aparelhos velhos, comprados em Campos. Ele pertencia ao Sr. Manuel Dias do Prado e hoje pertence ao Coronel Francisco Schmidt".

Podemos observar que o Cel. Schmidt investiu em vários negócios, comprando fazendas, plantando cafezais, instalando e comprando engenhos e usinas de açúcar, como também desenvolvendo a pecuária e investindo em imóveis e outras atividades produtivas.

O envolvimento do Cel. Francisco Schmidt nos negócios da industrialização de açúcar em São Paulo foi muito significativo. Além de comprar a Usina Cachoeira, em Franca, em 1903, fundou a Usina Schmidt, em 1906, no município de Sertãozinho, como também montou engenhoca na fazenda São Miguel. Na fazenda Monte Alegre, sua primeira propriedade de Ribeirão Preto, possuía dois engenhos, conforme MELLO MORAES (1982):

\begin{abstract}
"A fazenda Monte Alegre, além do café, tinha lavoura de cana-de-açúcar (...); existem na fazenda dois bem montados engenhos. $A$ produção anual ascende a 30.000 sacos de 60 kilos".
\end{abstract}

Em 1920, o Cel. Schmidt adquiriu, juntamente com o Conde Francisco Matarazzo e Cia. Mecânica e Imp. de São Paulo, a Usina London, da família Henrique Dumont e também nessa época fundou a Usina Albertina, em Sertãozinho.

Assim, procuramos demonstrar que os casos Dumont e Schmidt retratam o deslocamento contínuo dos lucros da cafeicultura para a industrialização do açúcar em São Paulo, independente das crises da cultura cafeeira.

\section{BIBLIOGRAFIA}

BRAY, Silvio C. A Cultura de Cana-de-Açúcar no Vale do Paranapanema: Um Estudo de Geografia Agrária. Tese de Doutoramento, São Paulo, F.F.C.H. da USP, 1980.

BRAY, Silvio C. A Questão da Formação do Capital na Agroindústria Açucareira Paulista nos Fins do Século XIX e Início do Século $X X$ : O Caso da Usina London. IN: ENCONTRO NACIONAL DE GEOGRAFIA AGRÁRIA, 7, Belo Horizonte, 1986.

BRAY, Silvio C. - A Formação do Capital na Agroindústria Açucareira de São Paulo: Revisão dos Paradígmas. Tese LivreDocência, Rio Claro, IGCE, UNESP, 1989.

CANO, Wilson. Raízes da Concentração Industrial em São Paulo, São Paulo, Editora Difel, 1977.

CARLI, Gileno de. Gênese e Evolução da Indústria Açucareira de São Paulo. Rio de Janeiro. Irmãos Pongetti, Editores, 1943.

DEAN, Warren . A Industrialização em São Paulo: 1880 a 1945. São Paulo, Difel, 1971.

FERREIRA, Enéas R. A Formação da Região Canavieira de Araraquara: O Papel do Estado e das Agroindústrias do Açúcar e do Álcool no Processo de Organização do Espaço. Dissertação de Mestrado, IGCE, UNESP, Rio Claro, São Paulo, 1987.

GNACCARINI, José A. Estado, Ideologia e Ação Empresarial na Agroindústria Açucareira do Estado de São Paulo. Tese de Doutoramento, São Paulo, F.F.L.C.H. da USP, 1972.

LACERDA de Mello, M. Aspectos da Geografia do Açúcar no Brasil. Revista Brasiliense de Geografia, CNG, IBGE, Rio de Janeiro 16(4) - 467/488, 1954. 
MELLO Moraes, M.L. de. Francisco Schmidt: A Formação de uma Grande Propriedade Cafeeira. História, UNESP, São Paulo, 1982, 1: 77-90.

MEYER, Antonio C. A Cultura da Cana e a Indústria Açucareira em São Paulo. São Paulo, Revista dos Tribunais, 1941.

NEGRI, Barjas. Um Estudo de Caso da Indústria Nacional de Equipamentos: Análise do Grupo Dedini (1920-1975). Dissertação de Mestrado, Campinas, I.F.C.H. da UNICAMP, 1977.

PESTANA, Paulo R. - A Riqueza Paulista. São Paulo, Typ. Brazil de Rothschild \& Co, 1920.

QUEDA, Oriowaldo. A Intervenção do Estado e a Agroindústria Açucareira Paulista. Tese de Doutoramento, ESALQ, USP, Piracicaba, São Paulo, 1972.

RAMOS, Pedro. Um Estudo da Evolução e da Estrutura da Agroindústria Canavieira do Estado de São Paulo: 1930-1982. Dissertação de Mestrado, Escola de Administração de Empresa de São Paulo, FGV, 1983.

REIS Garcia, Liliana B. O Processo de Formação do Capital Industrial no Estado de São Paulo. Geografia, Rio Claro, 1985, 10 (20): 61-97.

SAWYER, Frederic H. Estudo sobre a Indústria Açucareira no Estado de São Paulo. São Paulo, Typographia Brazil de Carlos Gekke \& Rothschild, 1905.

SECRETARIA da Agricultura, Commercio e Obras Públicas do Estado de São Paulo. Boletim de Agricultura (1911), São Paulo, 12(1): 47-48.

SECRETARIA da Agricultura, Commercio e Obras Públicas do Estado de São Paulo. $O$ Café (1915), São Paulo, Estatísticas de Produção e Comércio.
SECRETARIA da Agricultura, Comércio e Obras Públicas. Lavouras de Canna e de Algodão e Industrias do Assucar e de Tecidos, no Estado de São Paulo. Boletim de Agricultura (1903), São Paulo, 4(1): 559-600.

SELLINGARDI Sampaio, S. Geografia Industrial de Piracicaba. Um Exemplo de Interção Indústria-Agricultura. Tese de Doutoramento, F.F.C.L. de Rio Claro, Rio Claro, São Paulo, 1973.

SINGER, Paul I. Desenvolvimento Econômico e Evolução Urbana. São Paulo. Editora da Universidade de São Paulo, 1968.

VIZIOLI, José. A Presente Situação da Indústria Assucareira no Estado de São Paulo. Boletim de Agricultura, São Paulo, 1926, 27 (10): 321-366.

ZAMBONI, Silvio P. O Café no Norte Paulista: A Crise de 1929 na Fazenda Dumont. Dissertação de Mestrado, ESALQ, USP, Piracicaba, São Paulo, 1979. 